\title{
Leadership and Organizational Learning: The Determinants of Innovation Speed and Innovation Quality in Vietnamese Firms
}

\author{
Ha Thi Lan Anh ${ }^{1}$, Le Ba Phong ${ }^{1 \& 2} \&$ Lei Hui ${ }^{1}$ \\ ${ }^{1}$ School of Business Administration, Hunan University, Changsha, Hunan, China \\ ${ }^{2}$ Faculty of Business Management, Hanoi University of Industry, BacTuLiem, Hanoi, Vietnam \\ Correspondence: Lei Hui, School of Business Administration, Hunan University, Changsha, Hunan, China.
}

Received: January 17, 2019

doi:10.5430/jms.v10n1p29
Accepted: February 7, 2019

Online Published: February 12, 2019

URL: https://doi.org/10.5430/jms.v10n1p29

\begin{abstract}
The purpose of this study is to explore the influences of transformational leadership on organizational learning and how it relates to innovation speed and innovation quality. The paper uses structural equations modeling (SEM) to investigate the correlation between the constructs based on analyzing the empirical data collected from 250 small and medium firms in Vietnam. The results support positive and significant effects of transformational leadership on organizational learning and two aspects of innovation namely innovation speed and innovation quality. It also confirms that organizational learning acts as a mediator between transformational leadership and two types of innovation. The findings, therefore, provide clearer understanding of the relationship between transformation leadership, organizational learning and aspects of innovation. It provides managers the useful knowledge and specific pathway to enhance firm's innovation capability to effectively response to the rapid changes of business environment.
\end{abstract}

Keywords: transformational leadership, organizational learning, innovation speed, innovation quality, SEM

\section{Introduction}

Before the complex and rapid changes of business environment, innovation is fast becoming a crucial factor to improve firm performance and help firm survival (Campos \& Pablos, 2004; Le \& Lei, 2018). Firms realized that innovation capability is the key and decisive solution for them to create value, to build, and to sustain competitive advantage in long term as it can be a source of competitive advantage (Hinterhuber \& Liozu, 2014). Innovation helps firms adapt well with the uncertainty of the external environment and become one of the most important factors leading to the success of the business in the dynamic markets (Baker \& Sinkula, 2002; Hui et al., 2018; Yang et al., 2018).

Innovation capability is widely accepted as the key antecedent for firm to create and sustain competitive advantage, but many firms do not how to develop it properly (Hui et al., 2018; Le \& Lei, 2018; Lei et al., 2019). To provide more understanding or effective pathway leads to innovation, this study focus on investigating the influences of transformational leadership on two aspects of innovation capability namely innovation speed and innovation quality through the mediating role of organizational learning. This study is urgent and necessary by following issues.

First, many prior works have been done to explore the influences of transformational leadership (García-Morales et al., 2012; Hui et al., 2018), organizational learning (Liao et al., 2008; Le \& Lei, 2018), and other factors such as organizational culture (Yang et al., 2018), knowledge sharing (Lei et al., 2019) on firm innovation capability, but scholars mostly exam innovation capability in general point of view or at two aspects of product innovation and process innovation. Few study investigated the relationship between transformational leadership, organizational learning and two specific aspects of innovation capability namely innovation speed and innovation quality. Meanwhile innovation speed and innovation quality are seen as two critical aspects of innovation in complex and competition business environments (Le \& Lei, 2018).

Second, organizational learning is recognized as a strategic resource for maintaining long-term organizational success (García-Morales et al., 2012; Lei et al., 2017; Le \& Lei, 2018), as a result many scholars emphasized the necessity of exploring the consequences of learning capability (e.g., Prieto \& Revilla, 2006; Le \& Lei, 2018). 
Therefore, this study will increase the understanding of organizational learning theory by investigating clearer the different influences of organizational learning on innovation speed and innovation quality.

Finally, prior studies considered transformation leadership as one of the most important leadership styles that significantly influences on both innovation capability (McDonough, 2000; Harborne \& Johne, 2003; Hui et al., 2018), and organizational learning (Zagoršek et al., 2009; García-Morales et al., 2012). However few research investigated the mediating role of organizational learning between transformational leadership and specific aspects of innovation such as innovation speed, and innovation quality.

It is clearly that, although prior researches have made a considerable contribution to the understanding of the correlation between transformational leadership, organizational learning and innovation, empirical research on the relationship between transformational leadership, organizational learning and two key aspects of innovation capability is still sparse. To fill the theoretical gaps addressed above, and to contribute better knowledge about the relationship between these constructs, we use the structural equation modeling to test the level of influence that independent factor has on the dependent factors based on a survey of 250 participants from 102 small and medium enterprises in Vietnam. This study focus on addressing three research questions as following:

1. Does transformational leadership positive affect organizational learning and aspects of innovation?

2. Does organizational learning mediates the relationship between transformational leadership and two aspects of innovation?

By answer the above research question, this study is expected to offer specific and useful guidance for leaders to successfully improve innovation capabilities of their firms.

\section{Conceptual Background and Hypotheses}

\subsection{Transformational Leadership and Organizational Learning}

Organizational learning is a conception build by the integration of many behavior sciences such as psychology, organizational development, management science (Jiang \& Chen, 2017). According to Ford et al. (2011) organizational learning refers to an organization that flexibly distributes and effectively applies resources by enhance the overall learning capability aimed at developing the leverage effect of existing practice capability and creating new practice capability to cope with internal and external challenges at any time. Definition of organizational learning can be interpreted as many ways. Senge (1990) considered organizational learning a dynamically balanced relationship in which organizations acquire external knowledge and further adjust organization activities to help organization survive and grow. Slater and Narver (1995) proposed that organizational learning is a process that includes four main components of information acquisition, knowledge dissemination, shared interpretation and organizational memory. Organizational learning helps firms to develop mechanisms and processes encouraging both individual and group workplace learning (Armstrong \& Foley, 2003). In general, we define organizational learning as a flexibly process that unendingly create, share, disseminate and integrate new knowledge and information to effectively distribute, use its resources, and create valuable capabilities to cope well with business environment's internal and external challenges.

Transformational leadership is well known as one of the higher-ranking leadership styles. It describes the leaders who have capabilities of inspiring the employees to get the highest degrees of achievement and outcomes; stimulating employees to achieve goals further away than expectations; and persuading employees to pass self-interest for the organization's common utilities (Bass, 1985; Le \& Lei, 2017). Literature supports the positive correlation between transformational leadership and organizational learning (e.g., McDonough, 2000; Aragón-Correa et al., 2007; Chang \& Lee, 2007; Sattayaraksa \& Boon-itt, 2017). According to Coad and Berry (1998), transformational leadership fostered organizational learning through promoting intellectual stimulation, inspirational motivation, and self-confidence among organization members. McDonough (2000) indicated that transformational leaders build groups and offer them direction, energy. They also support processes of change and organizational learning. This helps firms to learn through experimentation, exploration, communication and dialogue (Slater \& Narver, 1995; Lei et al., 2000).

More specifically, Aragón-Correa et al. (2007) argued that transformational leaders fuel organizational learning by promoting intellectual stimulation, inspirational motivation, and self-confidence among employees in an organization. These authors conclude that a capability of transformational leadership can be seen as one of the most important means of developing learning organizations. Recently, Sattayaraksa and Boon-itt (2017) point out that, transformational leadership is positively associated with organizational learning because transformational leaders 
create an appropriate and conducive atmosphere to facilitate for process of successful generation and sharing and applying of knowledge. Based on above arguments, the following hypothesis is offered for testing (see Figure 1).

H1: Transformational leadership is positively related to organizational learning.

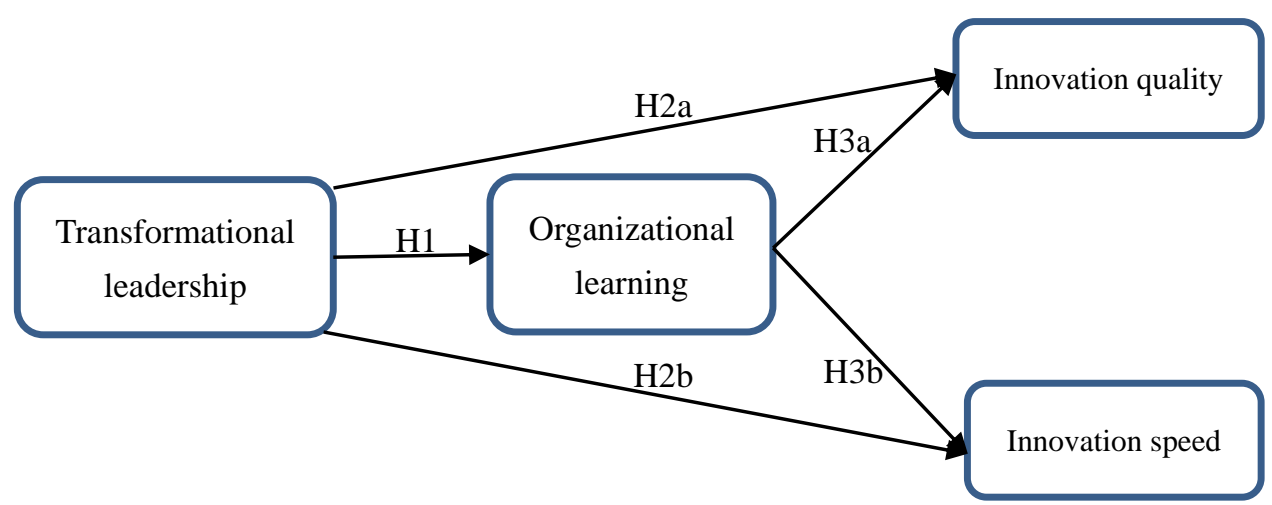

Figure 1. The conceptual model of the research

\subsection{Transformational Leadership and Innovation Capability}

Firms that successfully managed innovation can go beyond research and development to ensure that innovation is an integral part of their organizations and their extended value chains (Podrug et al., 2017). Scholars considered innovation as the capabilities of development and implementation of new ideas or behavior relating to a system, policy, program, device, process, product or service by people who engage in transactions over time with others within an organization (Hage, 1999; Podrug et al., 2017). Innovation can be classified into various categories. However, innovation speed and innovation quality are seen as two critical aspects of innovation (Le \& Lei, 2018) as a result this study focuses on investigating the relationship between these two aspects with transformational leadership. Innovation speed is a key element to compete in the market, for it can result in superior performance (Carbonell \& Rodriguez, 2006). Innovation speed refers to a firm's ability in shortening the creation of new products or processes relative to the competitors (Allocca \& Kessler, 2006; Le \& Lei, 2018); and innovation quality refers to a firm's ability in improving new management, processes and supply new products and services with better quality than key competitors (Wang et al., 2016; Le \& Lei, 2018).

Prior works have highlighted the positive influence of transformational leadership on innovation capability (e.g., Jung et al., 2003; Moriano et al., 2014; Le \& Lei, 2019). For example: Jung et al. (2003) supposed that transformational leadership is significantly and positively associated with firm innovation due to it is mediated by an organizational culture which encouraged employees freely in discussing and trying out innovative ideas and approaches. According to Gumusluoglu and Ilsev (2009), transformational leaders, who intellectually stimulate workers, articulate a strong vision, and emphasize innovation, help cultivating an organizational climate where followers feel challenged to find innovative solutions. Moriano et al. (2014) manifested that transformational leadership positively related to innovativeness and risk taking which are key antecedents of innovation capability. Recently, Sattayaraksa and Boon-itt (2017) stated that transformational leadership can be instrumental in shaping and instilling an innovation culture that encourages creativity, risk taking, and nurtures innovation.

Although transformational leadership is widely accepted as one of the most important factors positively related to innovation capability, however the correlation between transformational leadership and specific aspects of innovation capability namely innovation speed and innovation quality is still very scarce. These arguments lead to the next hypothesis:

H2a: Transformational leadership positively affects innovation quality.

H2b: Transformational leadership positively affects innovation speed.

\subsection{Organizational Learning and Innovation Capability}

Regarding the relationship between organizational learning an innovation capability, many researches in the growing literature on the topic of organizational learning have indicated a positive correlation between organizational learning and innovation capability (Hurley \& Hult, 1998; Calantone et al., 2002; Aragón-Correa et al., 2007; Wang \& Wang, 
2012; Song, 2015; Podrug et al., 2017). These works reported that organizational learning supports creativity, inspires new knowledge and ideas, and increases ability to understand and apply them. Specifically, Hurley and Hult (1998) highlighted that organizational learning plays a pivotal role in building and improving innovation capability. According to Calantone et al. (2002), organizational learning has a stronger capacity to understand rivals' strengths and weaknesses and thus to learn from their successes and their failures and to generate greater innovative capability than competitors. Aragón-Correa et al. (2007) denoted that generative learning, the most advanced form of organizational learning, is a necessary underpinning for radical innovations in products and processes. Wang and Wang (2012) proved that the process of sharing knowledge and information in an organization has a positive influence on both innovation speed and innovation quality. Song (2015) investigated the effect of organizational learning on innovation and indicated that organizational learning is a crucial factor that positively affects innovation in Chinese firms.

As discussion above, the positive relationships between organizational learning and innovation capability is quite clear, few researches examine the specific influences of organizational learning on innovation speed and innovation quality. To fill in the gaps, this study proposes following hypotheses:

H3a: Organizational learning is positively associated with innovation quality.

H3b: Organizational learning is positively associated with innovation speed.

\section{Research Methodology}

\subsection{Sample and Measures}

This study examined a sample of 250 small and medium firms in some developed provinces of Vietnam. To meet research needs, the respondents in this study are leaders and managers to ensure that they have clear knowledge on their firms. This study issues 525 questionnaires and receives 295. At last, 286 are valid, with a $47.67 \%$ valid rate.

To make certain of the research's the validity and reliability, items used to measure variables were developed from previous studies. All constructs were measured using multiple items and all items were evaluated using a five-point Likert-type scale, ranging from ' $1=$ strongly disagree' to ' $5=$ strongly agree'. To measure transformational leadership we use four items designed by Podsakoff et al. (1996). A sample item is "the firm's leaders are always on the lookout for new opportunities for the unit/department/organization". Organizational learning is measured by four items developed by Aragón et al (2007). A sample item is "The organization has acquired and shared much new and relevant knowledge that provided competitive advantage". To measure innovation speed and innovation quality, we use 10 items derived from the work of Le \& Lei (2018). Some samples items are "our firm is quick in new product launching as compared to key competitors" (innovation speed); and "our firm does better in new product development as compared to key competitors" (innovation quality).

\subsection{Data Analysis Methods}

To eliminate the effects of common method bias, this study applied Harman's single-factor test to test for common method bias. The consequence indicates the overall variance is less than the 50\% threshold for substantive common method variance. This specifies that common method bias was not a concern. In addition, to obtain the study's goal, we use analysis of moment structures (AMOS) to measure validation and for testing the structural model through the data gathered from the 250 small and medium firms in Vietnam.

\section{Result}

\subsection{Measurement Testing}

To examine the internal consistency of the variables, the coefficient of Cronbach's alpha $(\mathrm{C} \alpha)$ and item to total correlation are adopted. With result's statistic ranges from 0.78 to 0.91 , which are exceed 0.7 , it means high reliability (Nunnally \& Bernstein, 1994). We test exploratory factor analysis (EFA) to eliminate factors (factor loading lower than 0.5) to ensure the practicality of the research (Hair at al., 1998). We then performed confirmatory factor analysis (CFA) to evaluate the overall measurement model. Finally, we test convergent validity and discriminant validity of the constructs according to criteria of Fornell and Larcker (1981). Results in Table 1 support the convergent validity and discriminant validity of the constructs. Table 1 shows basic descriptive statistics, AVE, $\mathrm{CR}, \mathrm{C} \alpha$ of all constructs. 
Table 1. Descriptive statistics and average variances extracted from constructs

\begin{tabular}{llllllllll}
\hline Construct & AVE & CR & C $\alpha$ & Mean & SD & TL & OL & IQ & IS \\
\hline Transformational leadership (TL) & 0.60 & 0.85 & 0.85 & 3,45 & 0.55 & 0.77 & & & \\
Organizational learning (OL) & 0.57 & 0.84 & 0.84 & 3.37 & 0.47 & 0.57 & 0.75 & & \\
Innovation quality (IQ) & 0.71 & 0.93 & 0.91 & 3.60 & 0.66 & 0.56 & 0.70 & 0.84 & \\
Innovation speed (ÍS) & 0.70 & 0.92 & 0.92 & 3.51 & 0.60 & 0.50 & 0.57 & 0.66 & 0.83
\end{tabular}

Notes: $\mathrm{C} \alpha \geq 0.7$; $\mathrm{CR} \geq 0.7$; $\mathrm{AVE} \geq 0.5$; SD: standard deviation. Diagonal elements (in bold) are the square root of the AVE; Off-diagonal elements are the correlations among constructs;

To measure the model's degree fit, we evaluated following indicators: absolute fit measures including Chi-square/df (CMIN/df), goodness of fit index (GFI) and root mean square error of approximation (RMSEA); incremental fit measures including normed fit index (NFI), adjusted goodness of fit index (AGFI) and comparative fit index (CFI); Table 2 confirms the adequate reliability and validity of the measurement model because all fit indices meet satisfactory levels.

Table 2. Indices of the CFA model

\begin{tabular}{lll}
\hline Fit index & Scores & Recommended threshold value \\
\hline Absolute fit measures & & \\
CMIN/df & 1.474 & $\leq 2^{\mathrm{a}} ; \leq 5^{\mathrm{b}}$ \\
GFI & 0.923 & $\geq 0.90^{\mathrm{a}} ; \geq 0.80^{\mathrm{b}}$ \\
RMSEA & 0.044 & $\leq 0.80^{\mathrm{a}} ; \leq 0.10^{\mathrm{b}}$ \\
Incremental fit measures & & \\
NFI & 0.941 & $\geq 0.90^{\mathrm{a}} ;$ \\
AGFI & 0.901 & $\geq 0.90^{\mathrm{a}} ; \geq 0.80^{\mathrm{b}}$ \\
CFI & 0.980 & $\geq 0.90^{\mathrm{a}} ;$ \\
\hline
\end{tabular}

Notes: Acceptability: acceptable; b Acceptability: marginal

\subsection{Structural Model}

This section presents the main results of our research (Table 3, Table 4 and Fig.2.)

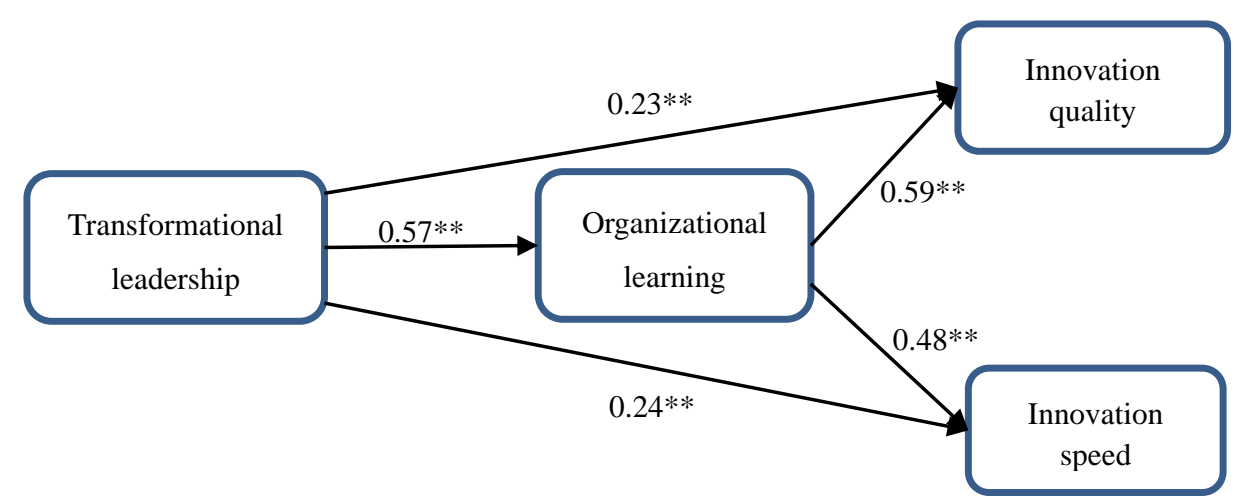

Figure 2. Results of the structural equation model 
Table 3. Structural model results

\begin{tabular}{lccll}
\hline Hypotheses & Proposal effect & Estimate & $\mathrm{P}$ & Results \\
\hline $\mathrm{H} 1: \mathrm{TL} \rightarrow \mathrm{OL}$ & + & $0.576^{* * *}$ & $<0.001$ & Supported \\
$\mathrm{H} 2 \mathrm{a}: \mathrm{TL} \rightarrow \mathrm{IQ}$ & + & $0.232^{* * *}$ & $<0.001$ & Supported \\
$\mathrm{H} 2 \mathrm{~b}: \mathrm{TL} \rightarrow \mathrm{IS}$ & + & $0.241^{* * *}$ & $<0.001$ & Supported \\
$\mathrm{H} 3 \mathrm{a}: \mathrm{OL} \rightarrow \mathrm{IQ}$ & + & $0.598^{* * *}$ & $<0.001$ & Supported \\
$\mathrm{H} 3 \mathrm{~b}: \mathrm{OL} \rightarrow \mathrm{IS}$ & + & $0.480^{* * *}$ & $<0.001$ & Supported \\
\hline
\end{tabular}

Notes: *** Significant at the 0,001 level

The results (Table 3 and Figure 2) indicated that the effect of transformational leadership on organizational learning is statistically significant and quite large, it supports hypothesis $\mathrm{H} 1$ relating to the positive effect of TL on OL with the values of $0.576(p<0.001)$

Hypothesis of $\mathrm{H} 2 \mathrm{a}$ and $\mathrm{H} 2 \mathrm{~b}$ relating to the positive effect of transformational leadership on innovation quality and innovation speed are also supported. With estimate value is $0.241(p<0.001)$, the result demonstrated that transformational leadership's effect on innovation speed is greater than its effect on innovation quality with the value of $0.232(p<0.001)$.

The results also confirm hypothesis of $\mathrm{H} 3 \mathrm{a}$ and $\mathrm{H} 3 \mathrm{~b}$ relating to the positive effect of organizational learning on innovation quality and innovation speed. The findings show that organizational learning has greater impacts on innovation quality (the value of $0.598 ; p<0.001$ ) in comparison with its impacts on innovation speed (the value of $0.480 ; p<0.001)$

To explore the mediating mechanism of how organizational leadership affects two aspects of innovation, Bootstrap procedure is performed to evaluate the confidence of indirect effect. The Table 4 shows the direct, indirect, and total effects in structural model.

Table 4. Direct, indirect and total effects analysis

\begin{tabular}{lccc}
\hline Predictor/dependent & OL & IQ & IS \\
\hline Direct effects & & & \\
Transformational leadership & $0.576^{* * * *}$ & $0.232^{* * *}$ & $0.241^{* * *}$ \\
Organizational learning & & $0.598^{* * * *}$ & $0.480^{* * *}$ \\
Indirect effects & & & \\
Transformational leadership & & $0.344^{* * *}$ & $0.276^{* * *}$ \\
Total effects & & & \\
Transformational leadership & & $0.576^{* * *}$ & $0.517^{* * *}$ \\
\hline
\end{tabular}

Notes: *** Significant at the 0,001 level

As to the indirect effects, table 4 firstly confirms the mediating role of organizational learning in the relationship between transformational leadership and two aspects of innovation capability. In addition, the findings show that, the indirect effects of transformational leadership on innovation quality is higher than its indirect effects on innovation speed $(0.344>0.276)$. Referring total effects, Table 4 indicated that total effects of transformational leadership on innovation quality is higher than its effects on innovation speed $(0.576>0.517)$.

\section{Discussions and Conclusions}

Although firm innovation capability is widely prescribed as a driving force to improving organizational performance (Hurley \& Hult, 1998; Garcia-Morales et al., 2008), many firms do not know how to develop it properly (Garcia-Morales et al., 2008; Le \& Lei, 2018). This leads to attention or motivation among researchers to look for what enables firms to innovate (Zollo \& Winter, 2002; Le \& Lei, 2018). Accordingly, this study significantly contributes to the improvement of innovation management theory by showing that innovation speed and innovation 
quality may be implemented based on multiple and simultaneous influences of individual and collective features. Specifically, the results support all proposal hypotheses and indicate that both transformational leadership style and the collective capability of organizational learning have positive influences on two specific aspects of innovation namely innovation speed and innovation quality. From these findings, the major implication of the paper is that, innovation is not available, and do not come to all organizations by natural, it occurs only in cases of firms having the appropriate internal characteristics, such as practice transformational leadership style by leaders or developing a model of organizational learning. In contrast, directors/managers may not successfully implement innovation (even when they have enormous resources) if they have no appropriate processes as well as understanding of complex condition that lead to achieve innovation. Transformational leadership and organizational learning are relevant examples of the internal conditions that firms need to build aimed at facilitating and improving innovation capability for their firms.

This study contributes to the literature in following ways. First, transformational leadership in firms is suggested by many authors to contribute to firm performance. Some studies empirically discussed the effects of transformational leadership on various aspects of innovation. However, few researches link transformational leadership, organizational learning, innovation speed and innovation quality from a holistic perspective. As a result, this study contributes to filling the theoretical gap by proposing the model and then providing an empirical evidence for the positive effect of transformational leadership on organizational learning which in turn positively affects two kinds of innovation capability namely innovation speed and innovation quality. Second, the findings showed that transformational leadership has not only direct influence but also indirect influence on two aspects of innovation based on mediating role of organizational learning, thereby affirming the mediating role of organizational learning in relationship between transformational leadership and aspects of innovation capability. Third, the findings also highlight that transformational leadership and organizational learning has more significant impact on innovation quality in comparison with their effects on innovation speed. From this finding, the paper has contributed to increasing the understanding on specific solutions to successfully implement specific aspects of innovation capability, and firm's specific strategies. This finding can be served as the reference to develop competitive advantage based on differentiation. It is because of executing differentiation strategy firms need providing special goods and services with high quality and value. This requires firms focusing on developing its capability of innovation quality (Maruso \& Weinzimmer, 2015; McGee \& Shook, 2015).

This study has some limitations. First, this study just researched the definition, dimensions and consequences of organizational learning in general. Further researches should explore more deeply by accessing organizational learning based on four processes: information acquisition, knowledge dissemination, shared interpretation and organizational memory. Second, this study has not considered the effects of mediating or moderating variables (such as firm size, firm age, etc.) on the relationship between latent variables in the proposal research model. Future researches may explore deeper the relationship between the structures by adding some suggested mediators or moderators. Finally, this study is implemented in the context of small and medium firms, the future research might investigate the correlation among the construct in broad context to consolidate the findings of the paper.

Overall, our study has provided empirical evidence to highlight that transformational leadership and organizational learning significantly contribute to improve firm innovation capability. The findings are encouraged to bring more deeply understanding about the right pathway for directors/managers to follow aimed at enhancing organizational learning and two specific aspects of innovation in small and medium firms. Specifically, by paying great attention on practicing transformational leadership style, they can successfully foster learning capability and innovation capabilities for their firms.

\section{References}

Allocca, M. A., \& Kessler, E. H. (2006). Innovation speed in small and medium-sized enterprises. Creativity and Innovation Management, 15(3), 279-295. https://doi.org/10.1111/j.1467-8691.2006.00389.x

Aragón-Correa, J. A., García-Morales, V. J., \& Cordón-Pozo, E. (2007). Leadership and organizational learning's role on innovation and performance: Lessons from Spain. Industrial Marketing Management, 36(3), 349-359. https://doi.org/10.1016/j.indmarman.2005.09.006

Armstrong, A., \& Foley, P. (2003). Foundations for a learning organization: organization learning mechanisms. The Learning Organization, 10(2), 74-82. https://doi.org/10.1108/09696470910462085 
Baker, W. E., \& Sinkula, J. M. (2002). Market orientation, learning orientation and product innovation: delving into the organization's black box. Journal of Market-Focused Management, 5(1), 5-23. https://doi.org/10.1023/A:1012543911149

Bass, B. M. (1985). Leadership and performance beyond expectations. Free Press, Collier Macmillan.

Calantone, R. J., Cavusgil, S. T., \& Zhao, Y. (2002). Learning orientation, firm innovation capability, and firm $\begin{array}{lllll}\text { performance. Industrial } & \text { Marketing }\end{array}$ https://doi.org/10.1016/S0019-8501(01)00203-6

Campos, E. B., \& de Pablos, P. O. (2004). Innovation and learning in the knowledge-based economy: challenges for the firm. International Journal of Technology Management, 27(6), 531-532.

Chang, S.-C., \& Lee, M.-S. (2007). A study on relationship among leadership, organizational culture, the operation of learning organization and employees' job satisfaction. The Learning Organization, 14(2), 155-185. https://doi.org/10.1108/09696470710727014

Ford, R. C., Latham, G. P., \& Lennox, G. (2011). Mystery shoppers. Organizational Dynamics, 3(40), 157-164. https://doi.org/10.1016/j.orgdyn.2011.04.002

Fornell, C., \& Larcker, D. F. (1981). Evaluating structural equation models with unobservable variables and measurement error. Journal of Marketing Research, 18(1), 39-50. https://doi.org/10.1177/002224378101800104

García-Morales, V. J., Jiménez-Barrionuevo, M. M., \& Gutiérrez-Gutiérrez, L. (2012). Transformational leadership influence on organizational performance through organizational learning and innovation. Journal of Business Research, 65(7), 1040-1050. https://doi.org/10.1016/j.jbusres.2011.03.005

Garcia-Morales, V. J., Llorens-Montes, F. J., \& Verdu-Jover, A. J. (2008). The Effects of transformational leadership on organizational performance through knowledge and innovation. British Journal of Management, 19(4), 299-319. https://doi.org/10.1111/j.1467-8551.2007.00547.x

Gumusluoglu, L., \& Ilsev, A. (2009). Transformational leadership, creativity, and organizational innovation. Journal of Business Research, 62(4), 461-473. https://doi.org/10.1016/j.jbusres.2007.07.032

Hage, J. T. (1999). Organizational innovation and organizational change. Annual Review of Sociology, 597-622. https://doi.org/10.1146/annurev.soc.25.1.597

Harborne, P., \& Johne, A. (2003). Creating a project climate for successful product innovation. European Journal of Innovation Management, 6(2), 118-132. https://doi.org/10.1108/14601060310475273

Hinterhuber, A., \& Liozu, S. M. (2014). Is innovation in pricing your next source of competitive advantage?. Business Horizons, 57(3), 413-423. https://doi.org/10.1016/j.bushor.2014.01.002

Hui, L., Phouvong, S., \& Phong, L. B. (2018). Transformational Leadership Facilitates Innovation Capability: The Mediating Roles of Interpersonal Trust. International Journal of Business Administration, 9(3), 1-9. https://doi.org/10.5430/ijba.v9n3p1

Hurley, R. F., \& Hult, G. T. M. (1998). Innovation, market orientation, and organizational learning: an integration and empirical examination. The Journal of Marketing, 42-54. https://doi.org/10.1177/002224299806200303

Jiang, Y., \& Chen, W.-K. (2017). Effects of Organizational Trust on Organizational Learning and Creativity. EURASIA Journal of Mathematics Science and Technology Education, 13(6), 2057-2068. https://doi.org/10.12973/eurasia.2017.01213a

Jung, D. I., Chow, C., \& Wu, A. (2003). The role of transformational leadership in enhancing organizational innovation: Hypotheses and some preliminary findings. The Leadership Quarterly, 14(4), 525-544. https://doi.org/10.1016/S1048-9843(03)00050-X

Le, P. B., \& Lei, H. (2017). How transformational leadership supports knowledge sharing: Evidence from Chinese manufacturing and service firms. Chinese Management Studies, 11(3), 479-497. https://doi.org/10.1108/CMS-02-2017-0039

Le, P. B., \& Lei, H. (2018). The effects of innovation speed and quality on differentiation and low-cost competitive advantage: The case of Chinese firms. Chinese Management Studies, 12(2), 305-322. https://doi.org/10.1108/CMS-10-2016-0195 
Le, P. B., \& Lei, H. (2019). Determinants of innovation capability: the roles of transformational leadership, knowledge sharing and perceived organizational support. Journal of Knowledge Management. https://doi.org/10.1108/JKM-09-2018-0568

Lei, D., Slocum, J. W., \& Pitts, R. A. (2000). Designing organizations for competitive advantage: the power of unlearning and learning. $\quad$ Organizational Dynamics, $27(3), \quad$ 24-38. https://doi.org/10.1016/S0090-2616(99)90019-0

Lei, H., Le, P. B., \& Nguyen, H. T. H. (2017). How Collaborative Culture Supports for Competitive Advantage: The Mediating Role of Organizational Learning. International Journal of Business Administration, 8(2), 73-85. https://doi.org/10.5430/ijba.v8n2p73

Lei, H., Nguyen, T. T., \& Le, P. B. (2019). How knowledge sharing connects interpersonal trust and innovation capability: The moderating effect of leadership support. Chinese Management Studies.

Maruso, L. C., \& Weinzimmer, L. G. (2015). Developing a Normative Framework to Access Small-Firm Entry Strategies: A Resource-Based View. Journal of Small Business Strategy, 10(1), 1-12.

McDonough, E. F. (2000). Investigation of factors contributing to the success of cross-functional teams. Journal of Product Innovation Management, 17(3), 221-235. https://doi.org/10.1111/1540-5885.1730221

McGee, J. E., \& Shook, C. L. (2015). Repsponding to Industry Consolidation in Fragmented Industries: The Role of Capabilities in Small Business Survival. Journal of Small Business Strategy, 11(2), 21-32.

Moriano, J. A., Molero, F., Topa, G., \& Mangin, J. P. L. (2014). The influence of transformational leadership and organizational identification on intrapreneurship. International Entrepreneurship and Management Journal, 10(1), 103-119. https://doi.org/10.1007/s11365-011-0196-x

Nunnally, J. C., \& Bernstein, I. (1994). Elements of statistical description and estimation. Psychometric Theory (3rd ed.). McGraw-Hill , New York.

Podrug, N., Filipović, D., \& Kovač, M. (2017). Knowledge sharing and firm innovation capability in Croatian ICT companies. International Journal of Manpower, 38(4), 632-644. https://doi.org/10.1108/IJM-04-2016-0077

Podsakoff, P. M., MacKenzie, S. B., \& Bommer, W. H. (1996). Transformational leader behaviors and substitutes for leadership as determinants of employee satisfaction, commitment, trust, and organizational citizenship behaviors. Journal of Management, 22(2), 259-298. https://doi.org/10.1177/014920639602200204

Prieto, I. M., \& Revilla, E. (2006). Learning capability and business performance: a non-financial and financial assessment. The Learning Organization, 13(2), 166-185. https://doi.org/10.1108/09696470610645494

Sattayaraksa, T., \& Boon-Itt, S. (2017). The roles of CEO transformational leadership and organizational factors on product innovation performance. European Journal of Innovation Management.

Senge, P. (1990). The fifth discipline: The art and practice of organizational learning. New York.

Slater, S., \& Narver, J. (1995). Market orientation and the learning organisation. Journal of Marketing, 59(3), 63-74. https://doi.org/10.1177/002224299505900306

Song, Z. H. (2015). Organizational learning, absorptive capacity, imitation and innovation: Empirical analyses of 115 firms across China. Chinese Management Studies, 9(1), 97-113. https://doi.org/10.1108/CMS-05-2014-0092

Wang, Z., \& Wang, N. (2012). Knowledge sharing, innovation and firm performance. Expert Systems With Applications, 39(10), 8899-8908. https://doi.org/10.1016/j.eswa.2012.02.017

Wang, Z., Sharma, P. N., \& Cao, J. (2016). From knowledge sharing to firm performance: A predictive model comparison. Journal of Business Research, 69(10), 4650-4658. https://doi.org/10.1016/j.jbusres.2016.03.055

Yang, Z., Nguyen, V. T., \& Le, P. B. (2018). Knowledge sharing serves as a mediator between collaborative culture and innovation capability: an empirical research. Journal of Business \& Industrial Marketing, 33(7), 958-969.

Zagoršek, H., Dimovski, V., \& Škerlavaj, M. (2009). Transactional and transformational leadership impacts on organizational learning. Journal for East European Management Studies, 144-165. https://doi.org/10.5771/0949-6181-2009-2-144

Zollo, M., \& Winter, S. G. (2002). Deliberate learning and the evolution of dynamic capabilities. Organization Science, 13(3), 339-351. https://doi.org/10.1287/orsc.13.3.339.2780 